\title{
CYP2A6 and CYP2E1 polymorphisms in a Brazilian population living in Rio de Janeiro
}

A. Rossini, S. Soares Lima,

D.C.M. Rapozo, M. Faria,

R.M. Albano and L.F. Ribeiro Pinto
Departamento de Bioquímica, Instituto de Biologia Roberto Alcântara Gomes, Universidade do Estado do Rio de Janeiro, Rio de Janeiro, RJ, Brasil

\section{Correspondence}

L.F. Ribeiro Pinto

Departamento de Bioquímica IBRAG, UERJ

Av. 28 de Setembro, 87 fundos

4 o Andar

20551-013 Rio de Janeiro, RJ

Brasil

Fax: +55-21-2587-6136

E-mail: fpinto@uerj.br

......................

Received May 19, 2005 Accepted October 6, 2005 ......................

\section{Abstract}

Cytochrome P450 (CYP) is a superfamily of enzymes involved in the metabolism of endogenous compounds and xenobiotics. CYP2A6 catalyzes the oxidation of nicotine and the activation of carcinogens such as aflatoxin B1 and nitrosamines. CYP2E1 metabolizes ethanol and other low-molecular weight compounds and can also activate nitrosamines. The CYP2A6 and CYP2E1 genes are polymorphic, altering their catalytic activities and susceptibility to cancer and other diseases. A number of polymorphisms described are ethnic-dependent. In the present study, we determined the genotype and allele frequencies of the main CYP2A6 and CYP2E1 polymorphisms in a group of 289 volunteers recruited at the Central Laboratory of Hospital Universitário Pedro Ernesto. They had been residing in the city of Rio de Janeiro for at least 6 months and were divided into two groups according to skin color (white and non-white). The alleles were determined by allele specific PCR $(C Y P 2 A 6)$ or by PCR-RFLP (CYP2E1). The frequencies of the $C Y P 2 A 6^{*} 1 B$ and $C Y P 2 A 6^{*} 2$ alleles were 0.29 and 0.02 for white individuals and 0.24 and 0.01 for non-white individuals, respectively. The $C Y P 2 A 6 * 5$ allele was not found in the population studied. Regarding the $C Y P 2 E 1 * 5 B$ allele, we found a frequency of 0.07 in white individuals, which was statistically different $(\mathrm{P}<0.05)$ from that present in non-white individuals (0.03). CYP2E1*6 allele frequency was the same $(0.08)$ in both groups. The frequencies of $C Y P 2 A 6 * 1 B, C Y P 2 A 6 * 2$ and $C Y P 2 E 1 * 6$ alleles in Brazilians are similar to those found in Caucasians and African-Americans, but the frequency of the $C Y P 2 E 1 * 5 B$ allele is higher in Brazilians.

\section{Introduction}

Cytochrome P450 (CYP) is a superfamily of hemoproteins that plays an important role in the biotransformation of various xenobiotics and endogenous compounds (1). Several CYP enzymes can activate procarcinogens to genotoxic intermediates (2). Genetic poly-
Key words

- CYP2A6

- CYP2E1

- Polymorphism

- Brazil

- Ethnic groups ...................... 
to environmental carcinogens or endogenous compounds (4-7).

CYP2A6 is involved in the metabolism of several nitrosamines, particularly those present in tobacco smoke (1), and is also responsible for most of the metabolism of nicotine in humans (6). The CYP2A6 gene is located on chromosome 19, at 19q13.2, in a cluster with other genes of the $C Y P 2 A$ sub-family (CYP2A7 and $C Y P 2 A 13)$ and genes from other $C Y P 2$ sub-families $(C Y P 2 B 6$, $C Y P 2 F 1)$ (7). Within the CYP2A6 gene, more than 20 alleles have been described (3). The $C Y P 2 A 6$ wild-type allele was termed $C Y P 2 A 6 * 1 A$. The $C Y P 2 A 6 * 1 B$ allele presents a gene conversion with $C Y P 2 A 7$ in the 3 -untranslated region and its effect on CYP2A6 activity is not known. The CYP2A6*2 allele has a single point mutation (1799T $>$ A) leading to a single amino acid substitution $(\mathrm{L} 160 \mathrm{H})(8-10)$ and the $C Y P 2 A 6 * 5$ allele has a point mutation in exon $9(6582 \mathrm{G}>\mathrm{T})$ also leading to a single amino acid substitution $(\mathrm{G} 479 \mathrm{~V})$, as well as a gene conversion in the 3 '-untranslated region (11). The $C Y P 2 A 6 * 2$ and $C Y P 2 A 6 * 5$ alleles encode unstable and catalytically inactive enzymes.

CYP2E1 is an ethanol-inducible enzyme that metabolizes some low-molecular weight compounds such as ethanol, acetone, and nitrosamines (12). The CYP2E1 gene is located on the long arm of chromosome 10, at 10q24.3-qter (13) and several CYP2E1 polymorphisms have been identified (3). The wild-type allele $(C Y P 2 E 1 * 1 A)$ has an RsaI restriction site in the regulatory region of the gene, at -1053, and a restriction site for DraI in exon 6 , at 7632 . The $C Y P 2 E 1 * 5 B$ allele, detected by resistance to digestion by $R s a \mathrm{I}$, seems to be associated with changes at the transcriptional level, resulting in altered catalytic rates $(14,15)$. This allele shows a restriction site for PstI, characterized by a G > C substitution at -1293 . A second allele, CYP $2 E 1 * 6$, shows a $\mathrm{T}>\mathrm{A}$ substitution at 7632 and is not digested by DraI (16). However, its effect on CYP2E1 activity remains unclear $(15,16)$.

CYP2A6 and CYP2E1 genetic polymorphisms are ethnic dependent (17), and the polymorphic alleles can be more than ten times more frequent in Asians than in Caucasians $(5,6,17)$. However, little information is available about these genetic polymorphisms in multi-ethnic populations.

In the present study, we analyzed the frequency of $C Y P 2 A 6$ and $C Y P 2 E 1$ polymorphisms in individuals living in the city of Rio de Janeiro, a highly admixed population, because these polymorphisms can be involved in the susceptibility to various diseases related to tobacco smoking and alcohol drinking.

\section{Material and Methods}

\section{Study group}

A total of 289 individuals were included in the present study. The group was composed of outpatients recruited at Hospital Universitário Pedro Ernesto (HUPE, UERJ) during 1999, who had already been included in a previously published study (18). All volunteers had been residents of the metropolitan area of Rio de Janeiro for at least 6 months. To avoid selecting individuals presenting a specific pathology, the subjects were recruited at the central laboratory of the hospital, and those with a previous history of cancer were not included in the study. Information was obtained using a standardized questionnaire, including data on social habits and health problems. The group eligible for the study was classified as white (151 individuals) or non-white (138 individuals) according to skin color. The group of non-white individuals included 63 mulattos and 75 black individuals. The mean age of the individuals that took part in this study was 54.2 years (range: 20 to 85 years) (Table 1). There was no significant difference in mean age between white and non-white individuals. The study proposal and all ethical 
proceedings were approved by the Ethics Committee of HUPE, UERJ. All of the participants signed an informed consent form.

\section{Genotyping}

DNA extraction. Blood was collected into EDTA-containing tubes and DNA was extract from blood lymphocytes by proteinase $\mathrm{K} / \mathrm{SDS}$ digestion as described (19).

CYP2A6 polymorphisms. Genotyping for the $C Y P 2 A 6 * 1 B, C Y P 2 A 6^{*} 2$, and $C Y P 2 A 6 * 5$ alleles were performed as described by Oscarson et al. (10,11). Briefly, a two-step PCR method was used to detect $C Y P 2 A 6^{*} 1 B$ and $C Y P 2 A 6 * 5$ alleles. In the first PCR reaction (PCR I), a region from exon 8 to the 3' flanking region of $C Y P 2 A 6$ was specifically amplified. This PCR product was subsequently used as a template in the second allelespecific PCR reaction (PCR II). The PCR I was identical for each allele, and PCR II was carried out using specific primers for the amplification of $C Y P 2 A 6 * 1 B$ or $C Y P 2 A 6 * 5$ in separated reaction tubes. For $C Y P 2 A 6 * 2$ a similar approach was conducted. In the PCR I a region from exon 1 to exon 4 was amplified, followed by PCR II, with specific primers for the amplification of $C Y P 2 A \sigma^{*} 2$. The PCR II for $C Y P 2 A 6 * 1 B, C Y P 2 A 6 * 2$ or $C Y P 2 A 6 * 5$ always had a primer that amplified the wild-type or the polymorphic allele. The genotype was determined according to the amplification products in PCR II.

CYP2E1 polymorphisms. The genotyping assays for the $C Y P 2 E 1$ polymorphisms were performed by PCR-RFLP analysis. The $* 5 B$ allele was detected as described by Hayashi et al. (15), with modifications. After initial denaturation at $94^{\circ} \mathrm{C}$ for $4 \mathrm{~min}$, amplification was carried out for 35 cycles at $94^{\circ} \mathrm{C}$ for $60 \mathrm{~s}, 53^{\circ} \mathrm{C}$ for $80 \mathrm{~s}, 72^{\circ} \mathrm{C}$ for $90 \mathrm{~s}$, followed by a final extension at $72^{\circ} \mathrm{C}$ for $5 \mathrm{~min}$. Ten microliters of the PCR product ( $410 \mathrm{bp}$ ) was incubated with 2.5 U RsaI (Life Technologies, Carlsbad, CA, USA) and $8 \mu \mathrm{L}$ was incubated with $3.0 \mathrm{U}$ Pst (Life Technologies), and the resulting frag- ments were separated on $2.5 \%$ agarose gel stained with ethidium bromide. The digestion products according to the different genotypes are described in Table 2 . For allele $* 6$ determination, the PCR conditions were those previously described $(15,20)$. The amplification product $(10 \mu \mathrm{L})$ was incubated with $2.5 \mathrm{U}$ DraI (Life Technologies), and the products were separated on $10 \%$ polyacrylamide gel and stained with silver (21). Table 2 shows the genotypes, the restriction enzymes used and the corresponding sizes of the digestion products.

\section{Statistical analysis}

Data were analyzed statistically using the GraphPad Instat (GraphPad Software, Inc., San Diego, CA, USA) and Genepop (Genepop web version 3.4) software (22). Differences were considered to be significant at $\mathrm{P}<0.05$.

\begin{tabular}{|c|c|c|c|c|c|c|}
\hline \multirow[t]{2}{*}{ Color } & \multicolumn{2}{|c|}{ Men } & \multicolumn{2}{|c|}{ Women } & \multicolumn{2}{|c|}{ Total } \\
\hline & $\mathrm{N}$ & Age & $\mathrm{N}$ & Age & $N$ & Age \\
\hline Black & 21 & 55.9 & 54 & 56.9 & 75 & 56.7 \\
\hline Mulatto & 21 & 53.5 & 42 & 53.2 & 63 & 53.3 \\
\hline Non-white ${ }^{a}$ & 42 & 54.7 & 96 & 55.3 & 138 & 55.1 \\
\hline White & 64 & 49.8 & 87 & 55.9 & 151 & 53.3 \\
\hline Total $^{b}$ & 106 & 51.7 & 183 & 55.6 & 289 & 54.2 \\
\hline
\end{tabular}

aNon-white includes mulatto and black skin-colored individuals. bNon-white (black + mulatto) and white individuals.

Table 2. Size of the digestion products according to CYP2E1 genotype and different restriction enzymes used in their analysis.

\begin{tabular}{lccc}
\hline Genotype & Rsal digestion & Pst digestion & Dral digestion \\
\hline$c 1 / c 1\left({ }^{*} 1 A{ }^{*} 1 A\right)$ & 360 and $50 \mathrm{bp}$ & $410 \mathrm{bp}$ & - \\
$c 2 / c 2\left({ }^{*} 5 B /{ }^{*} 5 B\right)$ & $410 \mathrm{bp}$ & 290 and $120 \mathrm{bp}$ & - \\
$c 1 / c 2\left({ }^{*} 1 A /{ }^{*} 5 B\right)$ & 410,360 and $50 \mathrm{bp}$ & 410,290 and $120 \mathrm{bp}$ & - \\
$D / D\left({ }^{*} 1{ }^{*} 1 A\right)$ & - & - & 572,302 and $121 \mathrm{bp}$ \\
$C / C\left({ }^{*} 6 /{ }^{*} 6\right)$ & - & - & 874 and $121 \mathrm{bp}$ \\
$D / C\left({ }^{*} 1{ }^{*} 6\right)$ & - & - & $874,572,302$ and $121 \mathrm{bp}$ \\
\hline
\end{tabular}




\section{Results}

Table 3 shows the genotype frequencies of $C Y P 2 A 6$. The most frequent genotype was $* 1 A / * 1 A$, followed by $* 1 A / * 1 B$. The $* 2 / * 2$ genotype was found in only 1 volun-

Table 3. Frequencies (number and \% of individuals) of CYP2A6 and CYP2E1 genotypes.

\begin{tabular}{|c|c|c|c|c|c|}
\hline & Black & Mulatto & Non-white ${ }^{a}$ & White & Total ${ }^{b}$ \\
\hline \multicolumn{6}{|l|}{ CYP2A6 } \\
\hline $\mathrm{N}$ & 75 & 63 & 138 & 151 & 289 \\
\hline${ }^{*} 1 A /{ }^{*} 1 A$ & $41(54.7)$ & $38(60.3)$ & $79(57.2)$ & $70(46.4)$ & $149(51.6)$ \\
\hline${ }^{*} 1 A /{ }^{*} 1 B$ & $28(37.3)$ & $20(31.8)$ & $48(34.8)$ & $64(42.4)$ & 112 (38.8) \\
\hline${ }^{*} 1 B /{ }^{*} 1 B$ & $5(6.7)$ & $4(6.3)$ & $9(6.5)$ & $10(6.6)$ & $19(6.6)$ \\
\hline${ }^{*} 1 A /{ }^{*} 2$ & $1(1.3)$ & 0 & $1(0.7)$ & $4(2.6)$ & $5(1.7)$ \\
\hline${ }^{*} 1 B /{ }^{*} 2$ & 0 & 0 & 0 & $3(2.0)$ & $3(1.0)$ \\
\hline${ }^{*} 2 /{ }^{*} 2$ & 0 & $1(1.6)$ & $1(0.7)$ & 0 & $1(0.3)$ \\
\hline \multicolumn{6}{|c|}{ CYP2E1 (Rsal) } \\
\hline $\mathrm{N}$ & 75 & 63 & 138 & 151 & 289 \\
\hline${ }^{*} 1 A /{ }^{*} 1 A$ & $72(96.0)$ & $59(93.7)$ & $131(94.9)$ & $132(87.4)$ & $263(91.0)$ \\
\hline${ }^{*} 1 A /{ }^{*} 5 B$ & $2(2.7)$ & $4(6.3)$ & $6(4.4)$ & $17(11.3)$ & $23(8.0)$ \\
\hline${ }^{*} 5 B /{ }^{*} 5 B$ & $1(1.3)$ & 0 & $1(0.7)$ & $2(1.3)$ & $3(1.0)$ \\
\hline \multicolumn{6}{|c|}{ CYP2E1 (Dral) } \\
\hline $\mathrm{N}$ & 75 & 63 & 138 & 151 & 289 \\
\hline${ }^{*} 1 \mathrm{~A} /{ }^{*} 1 \mathrm{~A}$ & 65 (86.7) & $53(84.1)$ & $118(85.5)$ & $127(84.1)$ & 245 (84.8) \\
\hline${ }^{*} 1 A{ }^{*} 6$ & $9(12.0)$ & $10(15.9)$ & 19 (13.8) & $23(15.2)$ & $42(14.5)$ \\
\hline${ }^{*} 6 /{ }^{*} 6$ & $1(1.3)$ & 0 & $1(0.7)$ & $1(0.7)$ & $2(0.7)$ \\
\hline
\end{tabular}

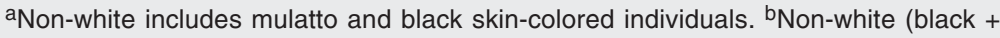
mulatto) and white individuals.

Table 4. CYP2A6 genotypes and allele frequencies in white and non-white Brazilian individuals.

$\frac{\text { Non-White }^{\mathrm{a}}}{\text { Observed Expected }} \quad \frac{\text { White }}{\text { Observed Expected }} \frac{\text { Total }^{\mathrm{b}}}{\text { Observed Expected }}$

\begin{tabular}{|c|c|c|c|c|c|c|c|c|}
\hline \multicolumn{9}{|l|}{ Genotype } \\
\hline${ }^{*} 1 A /{ }^{*} 1 A$ & 79 & & 77.5 & 70 & & 70.9 & 149 & 148.3 \\
\hline${ }^{*} 1 A /{ }^{*} 1 B$ & 48 & & 49.7 & 64 & & 60.5 & 112 & 110.4 \\
\hline${ }^{*} 1 B /{ }^{*} 1 B$ & 9 & & 7.8 & 10 & & 12.7 & 19 & 20.4 \\
\hline${ }^{*} 1 A / * 2$ & 1 & & 2.3 & 1 & & 2.8 & 2 & 5.1 \\
\hline$* 1 B / * 2$ & 0 & & 0.7 & 3 & & 1.2 & 3 & 1.9 \\
\hline${ }^{*} 2 /{ }^{*} 2$ & 1 & & 0.01 & 0 & & 0.02 & 1 & 0.04 \\
\hline$P$ & \multicolumn{3}{|c|}{0.018} & \multicolumn{3}{|c|}{0.108} & \multicolumn{2}{|c|}{0.015} \\
\hline \multirow[t]{2}{*}{ Allele frequency } & ${ }^{*} 1 A$ & ${ }^{*} 1 B$ & *2 & ${ }^{*} 1 A$ & ${ }^{*} 1 B$ & *2 & ${ }^{*} 1 A$ & $1 B$ \\
\hline & 0.75 & 0.24 & 0.01 & 0.69 & 0.29 & 0.02 & 0.72 & 0.01 \\
\hline
\end{tabular}

aNon-white includes mulatto and black skin-colored individuals. bNon-white (black + mulatto) and white individuals. teer, corresponding to a frequency of $0.3 \%$ in the study group. The frequency of the wild-type allele was 0.72 in the study population as a whole (Table 4), and 0.75 and 0.69 in non-white and white individuals, respectively. The $C Y P 2 A 6 * 5$ allele was absent in the individuals analyzed.

The frequencies of $R s a$ I genotype polymorphism of $C Y P 2 E 1$ in the population were $91 \%$ for the $* 1 A / * 1 A$ genotype, $8 \%$ for the $* 1 A / * 5 B$ genotype, and $1 \%$ for $* 5 B / * 5 B$ genotype (Table 3 ). Among non-white individuals, the respective frequencies were 94.9, 4.4 , and $0.7 \%$, whereas among white individuals the frequencies were $87.4 \%$ for $* 1 A$ / $* 1 A, 11.3 \%$ for $* 1 A / * 5 B$, and $1.3 \%$ for $* 5 B /$ $* 5 B$. When comparing white and non-white individuals we found a significant difference regarding these genotype frequencies $(\mathrm{P}<0.05)$, and the polymorphic allele $(* 5 B)$ was more frequent in white $(7 \%)$ than in non-white individuals (3\%; Table 5). As shown in Table 5, the population analyzed is not in Hardy-Weinberg equilibrium.

The genotype frequencies of the DraI polymorphism of the $C Y P 2 E 1$ gene were $84.8,14.5$, and $0.7 \%$ for the $* 1 A / * 1 A, * 1 A$ / $* 6$ and $* 6 / * 6$ genotypes, respectively (Table $3)$. There was no difference in genotype frequencies betwen white and non-white individuals, and the frequency of $C Y P 2 E 1 * 6$ was $8 \%$ in the population studied (Table 6).

\section{Discussion}

In Western countries, carcinogens present in tobacco smoke are the main substances involved in the development of tumors such as those of the lung (23) and the esophagus (24), among others. In most cases, there is a synergistic effect between tobacco smoking and alcohol drinking for the risk of tumor development $(24,25)$. Pro-carcinogens in tobacco smoke such as nitrosamines and ethanol are metabolized by CYP enzymes (1). CYP2A6 and CYP2E1 are the most important enzymes involved in nitrosamine 
activation in human tissues (1), and ethanol is metabolized by CYP2E1 and induces this enzyme. Therefore, polymorphisms in low penetrance genes like $C Y P 2 A 6$ and $C Y P 2 E 1$ can have an impact on cancer susceptibility (4), since polymorphic alleles encode proteins with altered catalytic activities or cause alterations in the regulation of the gene.

CYP2A6 genetic polymorphisms are also involved in the interindividual differences in nicotine disposition. Hepatic CYP2A6 catalyzes the $\mathrm{C}$-oxidation of nicotine to cotinine and the subsequent hydroxylation of cotinine to trans-3'-hydroxycotinine, the major route of nicotine metabolism (6). Thus, individuals showing reduced CYP2A6 activity determined by $C Y P 2 A 6$ genetic polymorphisms have impaired nicotine metabolism and reduced smoking behavior (6). In addition, these individuals may be less exposed to other tobacco compounds (6).

The Brazilian population consists of the admixture of Africans, Europeans and Amerindians, with a high degree of miscegenation $(26,27)$. This characteristic makes the Brazilian population different from other less admixed populations. Since it has been reported that $C Y P$ polymorphisms are ethnic dependent, in this study we determined the genotype and allele frequencies of $C Y P 2 A 6$ and $C Y P 2 E 1$ polymorphisms in a group of 289 volunteers from Rio de Janeiro.

The frequencies of the $C Y P 2 A \sigma^{*} 1 B$ and $C Y P 2 A 6^{*} 2$ alleles were 0.29 and 0.02 among white individuals and 0.24 and 0.01 among non-white individuals, respectively. Although not statistically significant, there was a trend to a lower frequency of these alleles among non-white individuals. These results agree with other studies that showed that these alleles seem to be less frequent among individuals of African ancestry $(6,28,29)$. Similar results were obtained in another study on Brazilian individuals (30), which found allele frequencies of 0.38 and 0.24 for $C Y P 2 A 6^{*} 1 B$ and 0.02 and 0.01 for $C Y P 2 A 6 * 2$ among white and non-white Bra- zilians, respectively. The results obtained for the population from Rio de Janeiro are similar to those obtained for Europeans and North Americans, whose allelic frequencies are about 0.30 for $C Y P 2 A 6^{*} 1 B$ and 0.01 0.03 for $C Y P 2 A 6^{*} 2$ among Caucasians (11, $28,31,32)$. We did not detect the presence of the $C Y P 2 A 6 * 5$ allele in the population studied. This allele has been shown to be very rare among Caucasians and Asians, with frequencies of 0-0.01 $(6,11,33)$. Recently, it was shown that $C Y P 2 A 6 * 5$ is absent in individuals from Africa (29).

In relation to the $R s a \mathrm{I}$ polymorphism of $C Y P 2 E 1$, we found genotype frequencies of 91,8 , and $1 \%$ for $* 1 A / * 1 A, * 1 A / * 5 B$, and

Table 5. CYP2E1 genotypes and allele frequencies (allele ${ }^{*} 5 B$ ) in white and nonwhite Brazilian individuals.

\begin{tabular}{|c|c|c|c|c|c|c|}
\hline & \multicolumn{2}{|c|}{ Non-White ${ }^{a}$} & \multicolumn{2}{|c|}{ White } & \multicolumn{2}{|c|}{ Total ${ }^{b}$} \\
\hline & Observed & Expected & Observed & Expected & Observed & Expected \\
\hline \multicolumn{7}{|l|}{ Genotype } \\
\hline${ }^{\star} 1 A /{ }^{*} 1 A$ & 131 & 130.1 & 132 & 130.7 & 263 & 260.7 \\
\hline${ }^{*} 1 A /{ }^{*} 5 B$ & 6 & 7.8 & 17 & 19.6 & 23 & 27.6 \\
\hline${ }^{*} 5 B /{ }^{*} 5 B$ & 1 & 0.1 & 2 & 0.7 & 3 & 0.7 \\
\hline $\mathrm{P}$ & \multicolumn{2}{|c|}{0.100} & \multicolumn{2}{|c|}{0.148} & \multicolumn{2}{|c|}{0.026} \\
\hline \multirow[t]{2}{*}{ Allele frequency } & ${ }^{*} 1 A$ & ${ }^{*} 5 B$ & ${ }^{*} 1 \mathrm{~A}$ & ${ }^{*} 5 B$ & ${ }^{*} 1 A$ & ${ }^{*} 5 B$ \\
\hline & 0.97 & 0.03 & 0.93 & 0.07 & 0.95 & 0.05 \\
\hline
\end{tabular}

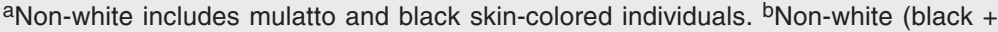
mulatto) and white individuals.

Table 6. CYP2E1 genotypes and allele frequencies (allele ${ }^{*} 6$ ) in white and nonwhite Brazilian individuals.

\begin{tabular}{|c|c|c|c|c|c|c|}
\hline & \multicolumn{2}{|c|}{ Non-White ${ }^{a}$} & \multicolumn{2}{|c|}{ White } & \multicolumn{2}{|c|}{ Total $^{b}$} \\
\hline & Observed & Expected & Observed & Expected & Observed & Expected \\
\hline \multicolumn{7}{|l|}{ Genotype } \\
\hline${ }^{*} 1 A /{ }^{*} 1 A$ & 118 & 117.7 & 127 & 127 & 245 & 244.8 \\
\hline${ }^{*} 1 A /{ }^{*} 6$ & 19 & 19.5 & 23 & 23 & 42 & 42.4 \\
\hline${ }^{*} 6 /{ }^{*} 6$ & 1 & 0.8 & 1 & 3 & 2 & 1.8 \\
\hline$P$ & \multicolumn{2}{|c|}{0.564} & \multicolumn{2}{|r|}{1.00} & \multicolumn{2}{|c|}{0.696} \\
\hline \multirow[t]{2}{*}{ Allele frequency } & ${ }^{*} 1 A$ & ${ }^{*} 6$ & *1A & ${ }^{*} 6$ & ${ }^{*} 1 A$ & ${ }^{*} 6$ \\
\hline & 0.92 & 0.08 & 0.92 & 0.08 & 0.92 & 0.08 \\
\hline
\end{tabular}

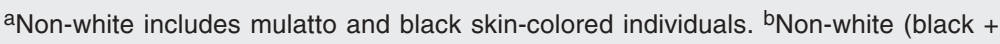
mulatto) and white individuals. 
$* 5 B / * 5 B$, respectively. Similar results were obtained in studies on volunteers from São Paulo, a State located near Rio de Janeiro. In those studies, the frequencies of the $* 1 A /$ $* 1 A, * 1 A / * 5 B$, and $* 5 B / * 5 B$ genotypes were $89.1,10.4$ and $0.5 \%$ (34), and 90,9 , and $1 \%$, respectively (35). The $* 5 B$ allele is significantly more frequent among white $(0.07)$ than among non-white individuals $(0.03 ; \mathrm{P}<$ 0.05 ). Differences in $C Y P 2 E 1 * 5 B$ allele frequencies between white and non-white individuals were also shown among North Americans $(36,37)$. The results obtained in the present study suggest that the polymorphic allele $C Y P 2 E 1 * 5 B$ is more frequent in Brazilians than in individuals from other Western populations, but less frequent than in Asians. The frequency of $C Y P 2 E 1 * 5 B$ was 0.03-0.04 in Germans and in European-Americans (36-38), and 0.003-0.01 in AfricanAmericans (36,37). Among Taiwanese individuals, the frequencies of $* 1 A / * 1 A, * 1 A /$ $* 5 B$, and $* 5 B / * 5 B$ genotypes were $58,35.1$, and $6.9 \%$, respectively (20), with an allele frequency of 0.24 for $C Y P 2 E 1 * 5 B$. In Chinese individuals, the frequency of the homozygous wild-type genotype was $6 \%$
$(39,40)$.

The DraI polymorphism of CYP2E1 (allele $C Y P 2 E 1^{*} \theta$ ) is also more frequent in Asians. Whereas $85 \%$ of our population (white and non-white) was homozygous for the wild-type allele, only half of the population from Asian countries presents this genotype $(17,20)$. The $C Y P 2 E 1 * 6$ allele frequency found in our study is similar to that found in other Western countries. The frequencies found for $C Y P 2 E 1 * 6$ were 0.08 among individuals from Rio de Janeiro, 0.09 among Germans (38), and 0.08 and 0.11 among African-Americans and Euro-Americans (36), respectively.

In the present study, we found differences between white and non-white individuals in the genotype and allele frequencies of $C Y P 2 A 6$ (alleles $* 1 B$ and $* 2$ ) and of $C Y P 2 E 1$ (allele $* 5 B$ ) gene polymorphisms, but not for the $C Y P 2 E 1 * 6$ allele. We also observed that the distributions of $C Y P 2 A 6 * 1 B, C Y P 2 A 6 * 2$ and $C Y P 2 E 1 * 6$ alleles, but not of the $C Y P 2 E 1 * 5 B$ allele, among white and non-white individuals were similar to those of Caucasians and AfricanAmericans, respectively.

\section{References}

1. Hasler JA, Estabrook R, Murray M et al. (1999). Human cytochromes P450. Molecular Aspects of Medicine, 20: 1-137.

2. Rautio A (2003). Polymorphic CYP2A6 and its clinical and toxicological significance. Pharmacogenomics Journal, 3: 6-7.

3. CYP Alleles Homepage [http://www.imm.ki.se/CYPalleles]. Accessed March 15, 2005.

4. Vineis $P$ (2002). The relationship between polymorphisms of xenobiotic metabolizing enzymes and susceptibility to cancer. Toxicology, 181-182: 457-462.

5. Daly AK (2003). Pharmacogenetics of the major polymorphic metabolizing enzymes. Fundamental and Clinical Pharmacology, 17: 27-41.

6. Tricker AR (2003). Nicotine metabolism, human drug metabolism polymorphisms, and smoking behaviour. Toxicology, 183: 151-173.

7. Fernandez-Salgueiro P \& Gonzalez FJ (1995). The CYP2A subfamily: species differences, regulation, catalytic activities and role in chemical carcinogenesis. Pharmacogenetics, 5: S123-S128.

8. Yamano S, Tatsuno J \& Gonzalez FJ (1990). The CYP2A3 gene product catalyzes coumarin 7-hydroxylation in human liver microsomes. Biochemistry, 29: 1322-1329.

9. Haddidi H, Zahlsen K, Idle JR et al. (1997). A single amino acid substitution (Leu160His) in cytochrome P450 CYP2A6 causes switching from 7-hydroxylation to 3-hydroxylation of coumarin. Food and Chemical Toxicology, 35: 903-907.

10. Oscarson M, Gullsten H, Rautio A et al. (1998). Genotyping of human cytochrome P450 2A6 (CYP2A6), a nicotine C-oxidase. FEBS Letters, 438: 201-205.

11. Oscarson M, McLellan RA, Gullstén H et al. (1999). Identification and characterisation of novel polymorphisms in the CYP2A locus: implications for nicotine metabolism. FEBS Letters, 460: 321-327.

12. Yang CS, Patten CJ, Ishizaki $\mathrm{H}$ et al. (1991). Induction, purification, and characterization of cytochrome P450IIE. Methods in Enzymology, 206: 595-601.

13. Umeno M, McBride OW, Yang CS et al. (1988). Human ethanolinducible P450lIE1: complete gene sequence, promoter characterization, chromosome mapping, and cDNA-directed expression. Bio- 
chemistry, 27: 9006-9013

14. Watanabe J, Hayashi S, Nakachi K et al. (1990). Pst I and Rsal RFLPs in complete linkage disequilibrium at the CYP2E gene. Nucleic Acids Research, 18: 7194.

15. Hayashi S, Watanabe J \& Kawajiri K (1991). Genetic polymorphisms in the 5'-flanking region change transcriptional regulation of the human cytochrome P450IIE1 gene. Journal of Biochemistry, 110: 559-565.

16. Persson I, Johansson I, Bergling H et al. (1993). Genetic polymorphism of cytochrome P4502E1 in a Swedish population. Relationship to incidence of lung cancer. FEBS Letters, 319: 207-211.

17. Garte S, Gaspari L, Alexandrie A et al. (2001). Metabolic gene polymorphism frequencies in control populations. Cancer Epidemiology, Biomarkers and Prevention, 10: 1239-1248.

18. Rossini A, Rapozo DCM, Amorim LMF et al. (2002). Frequencies of GSTM1, GSTT1, and GSTP1 polymorphisms in a Brazilian population. Genetics and Molecular Research, 1: 233-240.

19. Miller S, Dykes D \& Polesky H (1988). A simple salting out procedure for extracting DNA from human nucleated cells. Nucleic Acids Research, 16: 1215.

20. Wang S, Lee H, Chen K et al. (1999). Cytochrome P4502E1 genetic polymorphisms and lung cancer in a Taiwanese population. Lung Cancer, 26: 27-34.

21. Sanguinetti CJ, Neto ED \& Simpson AJG (1994). Rapid silver staining and recovery of PCR products separated on polyacrylamide gels. Biotechniques, 17: 915-919.

22. Genepop on the Web version 3.4. [http://wbiomed.curtin.edu.au/ genepop]. Accessed March 10, 2005.

23. Stellman SD, Takezaki T, Wang $L$ et al. (2001). Smoking and lung cancer risk in American and Japanese men: an international casecontrol study. Cancer Epidemiology, Biomarkers and Prevention, 10: 1193-1199.

24. Castellsagué X, Muñoz N, De Stefani E et al. (1999). Independent and joint effects of tobacco smoking and alcohol drinking on the risk of esophageal cancer in men and women. International Journal of Cancer, 82: 657-664.

25. Wynder EL, Mushinski MH \& Spivak JC (1977). Tobacco and alcohol consumption in relation to the development of multiple primary cancers. Cancer, 40: 1872-1878.

26. Carvalho-Silva DR, Santos FR, Rocha J et al. (2001). The phylogeography of Brazilian Y chromosome. American Journal of Human Genetics, 68: 281-286.

27. Parra FC, Amado RC, Lambertucci JR et al. (2003). Color and genomic ancestry in Brazilians. Proceedings of the National Academy of Sciences, USA, 100: 177-182.

28. Paschke T, Riefler M, Schuler-Metz A et al. (2001). Comparison of cytochrome P450 2A6 polymorphism frequencies in Caucasians and African Americans using a new one-step PCR-RFLP genotyping method. Toxicology, 168: 259-268.

29. Gyamfi MA, Fujieda M, Kiyotani K et al. (2005). High prevalence of cytochrome $P_{4502 A 6 * 1 A}$ alleles in a black African population of Ghana. European Journal of Clinical Pharmacology, 60: 855-857.

30. Vasconcelos GM, Struchiner CJ \& Suarez-Kurtz G (2005). CYP2A6 genetic polymorphisms and correlation with smoking status in Brazilians. Pharmacogenomics Journal, 5: 42-48.

31. Oscarson M, McLellan RA, Gullsten H et al. (1999). Characterisation and PCR-based detection of a CYP2A6 gene deletion found at a high frequency in a Chinese population. FEBS Letters, 448: 105110.

32. Bourian M, Gullstén H \& Legrum W (2000). Genetic polymorphism of CYP2A6 in the German population. Toxicology, 144: 129-137.

33. Kwon JT, Nakajima M, Chai S et al. (2001). Nicotine metabolism and CYP2A6 allele frequencies in Koreans. Pharmacogenetics, 11: 317323.

34. Burim RV, Canalle R, Martinelli ALC et al. (2004). Polymorphisms in glutathione S-transferases GSTM1, GSTT1 and GSTP1 and cytochromes P450 CYP2E1 and CYP1A1 and susceptibility to cirrhosis or pancreatitis in alcoholics. Mutagenesis, 19: 291-298.

35. Nishimoto IN, Hanaoka T, Sugimura H et al. (2000). Cytochrome P450 2E1 polymorphism in gastric cancer in Brazil: case-control studies of Japanese Brazilians and non-Japanese Brazilians. Cancer Epidemiology, Biomarkers and Prevention, 9: 675-680.

36. Stephens EA, Taylor JA, Kaplan $\mathrm{N}$ et al. (1994). Ethnic variation in the CYP2E1 gene: polymorphism analysis in 695 African-Americans, European-Americans and Taiwanese. Pharmacogenetics, 4: 185-192.

37. Liu S, Park JY, Schantz SP et al. (2001). Elucidation of CYP2E1 5' regulatory Rsal/Pstl allelic variants and their role in risk for oral cancer. Oral Oncology, 37: 437-445.

38. Neuhaus T, Ko Y, Lorenzen K et al. (2004). Association of cytochrome P450 2E1 polymorphisms and head and neck squamous cell cancer. Toxicology Letters, 151: 273-282.

39. Tan W, Song N, Wang G et al. (2000). Impact of genetic polymorphisms in cytochrome P450 2E1 and glutathione S-transferases M1, $T 1$, and $P 1$ on susceptibility to esophageal cancer among high-risk individuals in China. Cancer Epidemiology, Biomarkers and Prevention, 9: 551-556.

40. Gao C, Takezaki T, Wu J et al. (2002). Interaction between cytochrome p-450 2e1 polymorphisms and environmental factors with risk of esophageal and stomach cancers in Chinese. Cancer Epidemiology, Biomarkers and Prevention, 11: 29-34. 